\title{
HISTÓRIA DO CUIDADO AO RECÉM-NASCIDO NA MATERNIDADE CARMELA DUTRA - FLORIANÓPOLIS-SC/BRASIL (1956-2001)
}

\author{
History of the care of newborns at Maternity Carmela Dutra - Florianópolis - SC / \\ Brazil (1956-2001) \\ Historia del cuidado al recién nacido en la Maternidad Carmela Dutra - Florianópolis- \\ SC/ Brasil (1956-2001)
}

Vitória Regina Petters Gregório ${ }^{1} \quad$ Maria Itayra Padilha²

\section{RESUMO}

Pesquisa qualitativa de abordagem sócio-histórica com o objetivo de analisar as práticas de cuidado desenvolvidas, pelas enfermeiras, ao recém-nascido na Maternidade Carmela Dutra, Florianópolis-SC, no período de 1956 a 2001. Os sujeitos da pesquisa foram nove enfermeiras que trabalharam na Maternidade no período demarcado. Os dados foram categorizados utilizando-se análise de conteúdo temática com base no referencial foucaultiano. Emergiram três categorias: 0 bebê nascia e passava por uma janelinha para o berçário; As mães não eram donas dos filhos; 0 prematuro era bem embrulhadinho e levado da sala de parto para o berçário de alto risco. Os resultados mostraram que as práticas de cuidados prestadas aos recém-nascidos passaram por muitas transformações importantes e desafiantes para as enfermeiras. A pesquisa possibilitou conhecer o cotidiano do trabalho das enfermeiras, iluminando o interior das práticas de cuidado e as relações de poder-saber, fortalecendo sua identidade e colaborando para a construção profissional.

Palavras-chave: Enfermagem Obstétrica. Enfermagem Neonatal. História da Enfermagem. Saúde da criança.

\begin{abstract}
A qualitative study of socio-historical approach aiming to analyze the practices developed by nurses with newborns in the Maternity Carmela Dutra, Florianópolis - SC, from 1956 to 2001. The study subject were nine nurses who worked in the Maternity in the period demarcated. The data were categorized using thematic content analysis based on Foucaultian referential. Three categories emerged: The baby was born and passed through a window to the nursery; the mothers were not owners of their children; the premature was very well wrapped up and taken from the delivery room for the high-risk nursery. The results showed that the practices of care provided to newborns have gone through many major and challenging transformations for nurses. The results allow us to know the daily work of nurses, illuminating the interior of care practices and the relations of power-knowledge, strengthening their identity and contributing to the professional construction.
\end{abstract}

Keywords: Obstetrical Nursing. Neonatal Nursing. History of Nursing; Child Health.

\section{Resumen}

Investigación cualitativa con abordaje social e histórico que tiene el objetivo de analizar las prácticas de cuidado desarrolladas por las enfermeras al recién nacido en la Maternidad Carmela Dutra, Florianópolis-SC, durante el período desde 1956 hasta 2001. Los sujetos de la investigación fueron nueve enfermeras que trabajaron en la Maternidad durante el período demarcado. Los datos fueron categorizados utilizando el análisis de contenido temático con base en el referencial foucaultiano. Emergieron tres categorías: El bebé nacía y pasaba por una ventanita hasta la cuna; Las madres no eran las dueñas de los hijos; El prematuro era conducido de la sala de parto a la cuna de alto riesgo bien envuelto. Los resultados mostraron que las prácticas de cuidados prestadas a los recién nacidos pasó por muchas transformaciones importantes y desafiantes para las enfermeras. La pesquisa posibilitó conocer el cotidiano del trabajo de las enfermeras, iluminando el interior de las prácticas de cuidado y las relaciones de poder/saber, fortaleciendo su identidad y colaborando para la construcción profesional.

Palabras clave: Enfermería Obstétrica. Enfermería Neonatal. Historia de la Enfermería. Salud del Niño.

\footnotetext{
' Doutora em Enfermagem pelo Programa de Pós-Graduação em Enfermagem da Universidade Federal de Santa Catarina - PEN/UFSC. Docente do Depto de Enfermagem da UFSC. Florianópolis - SC. Brasil. E-mail: vitoria@nfr.ufsc.br; ${ }^{2}$ Professora Associada do Departamento de Enfermagem da UFSC. Docente PEN/UFSC. Doutora em Enfermagem pela Escola Anna Nery (UFRJ). Pós-Doutora pela Lawrence Bloomberg Faculty of Nursing at University of Toronto. Canadá. Pesquisadora do CNPq. Florianópolis - SC. Brasil. E-mail: padilha@nfr.ufsc.br
} 


\section{INTRODUÇÃO}

A história do cuidado prestado pela enfermeira na maternidade vem sendo recontada e reavaliada ao longo dos anos, seja por conta das mudanças sociais e culturais, mudanças nas rotinas das instituições, avanços tecnológicos ou avanços em termos de evidências científicas. Ressalta-se que o foco do cuidado, durante muitos anos, foi a mulher e as práticas obstétricas, não havendo significativa preocupação com 0 cuidado ao recém-nascido.

Em Florianópolis-SC, o cuidado às mulheres e aos recémnascidos no âmbito hospitalar teve seu início em junho de 1926, com a criação da Maternidade de Florianópolis, a qual teve seu nome modificado, em 30 de maio de 1948, para Maternidade Carlos Corrêa ${ }^{a}$.

Na década de 1950, em razão do aumento crescente do índice de natalidade e mortalidade infantil em Florianópolis, foi construída a segunda maternidade da cidade, a Maternidade Carmela Dutra (MCD), que tinha como objetivo atender mulheres e recém-nascidos de classes menos favorecidas. Inaugurada em três de julho de 1955, começou a atender as parturientes e os recém-nascidos somente em fevereiro de 1956, quando as Irmãs da Divina Providência assumiram a administração e a organização dos serviços ${ }^{2-3}$. Como parte dessa ação, em abril do mesmo ano, foi inserida a figura da enfermeira no cuidado à mulher e ao recém-nascido nessa maternidade, fato novo no cuidado hospitalar até então desenvolvido por médicos e parteiras.

Por compreender tal evento como um marco para a profissional enfermeira, tem-se como objetivo analisar as práticas de cuidado ao recém-nascido desenvolvidas pelas enfermeiras na MCD, no período de 1956 a 2001. Quanto ao tempo histórico, contemplou-se o período inicial de 1956 com o ingresso da primeira enfermeira na MCD, a Irmã Cacilda ${ }^{a}$ (nascida Ottille Hammes) e período final de 2001, com a posse da primeira enfermeira na direção da MCD, a Doutora Evanguelia Kotzias Atherino dos Santos, a qual exercia atividades como enfermeira nesta maternidade desde 1976. Embora o recorte histórico seja de longa duração, em razão das rupturas importantes advindas deste processo, entendemos a importância de compreendê-lo na sua totalidade.

\section{METODOLOGIA}

Trata-se de pesquisa qualitativa com abordagem sóciohistórica. A contribuição da pesquisa histórica para este trabalho está na possibilidade de promover o repensar sobre o período em foco, dando visibilidade às práticas de cuidado prestadas ao recém-nascido pelas enfermeiras da MCD participantes deste estudo.

Para a coleta de dados foi utilizada a técnica de história oral temática e também a pesquisa documental, em virtude da escassez de registros escritos referentes à participação das enfermeiras nas práticas de cuidado na MCD. Assim, as falas das enfermeiras foram necessárias para revelar os eventos e práticas de cuidado no período histórico estudado e complementar os exíguos documentos encontrados.

Os sujeitos da pesquisa foram nove enfermeiras que trabalharam na MCD entre 1956 e 2001, as quais foram entrevistadas de fevereiro a julho de 2009, por meio de um roteiro de entrevista semiestruturada usando a técnica "bola de neve", ${ }^{4}$ até a saturação dos dados. 0 roteiro de entrevista abordou o perfil das enfermeiras, as práticas de cuidado realizadas e o contexto da instituição. 0 tempo médio das entrevistas foi de três horas, e estas foram realizadas em locais de escolha das entrevistadas. Após transcrição, as entrevistas foram validadas pelos sujeitos do estudo.

As fontes documentais utilizadas foram: jornais, livros de passagem de plantão, livros de ocorrências, além de fotos da época.

Os dados foram analisados pela técnica de Análise de Conteúdo Temática de Minayo ${ }^{5}$, com base no referencial teóricofilosófico de Michel Foucault, especialmente no conceito de poder disciplinar, com o objetivo de estabelecer um diálogo com as bases filosóficas e históricas contemporâneas, ao pensar os acontecimentos do passado, na perspectiva de encontrar luz para interpretar a história do presente ${ }^{6}$. A análise dos dados revelou três categorias: 0 bebê nascia e passava por uma janelinha para o berçário; As mães não eram donas dos filhos; 0 prematuro era bem embrulhadinho e levado da sala de parto para o berçário de alto risco.

0 projeto de pesquisa foi avaliado pelo Comitê de Ética em Pesquisa com Seres Humanos da UFSC e aprovado com parecer exarado no protocolo $n^{0}$ 003/09. Os participantes assinaram o Termo de Consentimento Livre e Esclarecido, e a Carta de Cessão da entrevista e de uso de imagens fotográficas, de acordo com as Resoluções 196/96 e 251/97 do Conselho Nacional de Saúde. Na pesquisa histórica trabalha-se com nomes reais dos entrevistados e com os fatos, porque seu objetivo é historicizá-los, mas essa identidade poderia ser omitida se as entrevistadas assim o desejassem. Para o presente estudo, as entrevistadas concordaram que seus nomes fossem citados. Além disso, ao lado do nome de cada uma das entrevistadas incluímos o ano em que ela iniciou as suas atividades na MCD.

\section{RESULTADOS E DISCUSSÃO}

No período de 1956 a 2001, a MCD passou por várias transformações importantes, não apenas em sua estrutura física, mas também com relação a material, pessoal e comunicação. Na sua inauguração, em 1956, sua estrutura física era dotada de 30 leitos no berçário, 30 leitos no berçário de alto risco e quatro enfermarias com 11 leitos cada uma ${ }^{2-3}$. Em 2001, havia 10 leitos de UTI neonatal e 10 leitos de berçário de alto risco, além do Alojamento Conjunto, com 31 leitos para puérpera e 31 leitos para recém-nascidos, criado em 1996.

As enfermeiras da MCD, nesse período, prestaram cuidados em todos os espaços citados, para as mães e seus filhos das categorias indigentes ou assistidas pela previdência 
social. As enfermeiras que participaram do presente estudo demonstraram preocupação constante com a prevenção de infecções. Na década de 1950 quase não havia material descartável e as luvas, agulhas e seringas eram lavadas e preparadas nos setores, e esterilizadas no Centro de Material, em estufa e, posteriormente, em autoclave. Até mesmo fazer pedido de material era difícil; muitas vezes, os materiais não eram entregues nas especificações solicitadas ou não funcionavam adequadamente, e tinham de ser jogados fora. " 0 barato saía caro" referiu a enfermeira Sônia. As enfermeiras afirmaram que mudar a cultura de esterilização em estufa e autoclave para material descartável foi muito difícil. Para tanto, precisaram realizar um amplo trabalho de conscientização e provar que a utilização de material descartável era mais econômico para a instituição.

A falta de energia elétrica era frequente, precisandose recorrer à utilização das velas. Com a instalação do gerador, a situação foi contornada, proporcionando melhorias significativas, como refere a enfermeira:

"além de passar o plantão da paciente, as enfermeiras passavam o plantão das velas, porque se faltasse luz, as velas tinham que estar no lugar certo, para não ter problemas" (Sônia, 1979).

Na unidade de internação, para os profissionais de saúde lavarem as mãos era difícil, porque só havia pia no posto de enfermagem:

"a enfermeira não podia estar vigiando o posto de enfermagem toda hora [...] não dava para controlar tudo" (Doraci, 1976).

Percebe-se que as enfermeiras ansiavam por exercer um controle sobre 0 ambiente, o material e as ações da equipe, tanto em relação ao cuidado prestado ao recém-nascido, quanto com iluminação, limpeza e antissepsia. Estavam sempre atentas para suprir essas necessidades e desenvolver as atividades necessárias ao cuidado com qualidade. A questão do controle tem como consequência o poder disciplinar que, ao estilo de uma rede, permeia todo o corpo social e se constitui em uma relação de força que classifica, observa, registra e controla tudo e todos ${ }^{7}$.

No que diz respeito à comunicação entre os setores, ocorriam muitos problemas, pois os profissionais se comunicavam uns com os outros através da telefonista diretamente; tudo era feito por meio da telefonista. Quando a comunicação utilizava diversos interlocutores, como no caso da $M C D$, a mensagem final às vezes chegava alterada, gerando dúvidas e causando problemas. 0 processo de comunicação verbal, de forma direta, permite que os fatos sejam transmitidos de forma clara, sem vieses, além de promover a interação entre os profissionais da equipe de saúde.
Acreditando no poder do conhecimento técnicocientífico, as enfermeiras da MCD tentaram buscar soluções para os problemas que se apresentavam no cotidiano profissional e introduziram algumas mudanças no cuidado ao recém-nascido e à família, como se apresenta a seguir.

\section{0 bebê nascia e passava por uma janelinha para 0 berçário}

Na MCD, o nascimento dos bebês ocorria na sala de parto, podendo ser atendido pelo pediatra ou pelo acadêmico de medicina do último ano do Hospital Infantil (HI). Na ausência destes, os cuidados eram realizados pela enfermeira ou atendente de enfermagem. Em seguida, os neonatos eram "passados" para o berçário, ou seja, havia uma janela de ligação entre a sala de parto e o berçário, por onde o recém-nascido era entregue para a funcionária do setor.

"Chamava o pediatra ou o doutorando do Hospital Infantil que ficava anexo à MCD, ou eram feitos por nós mesmos a aspiração, limpeza, identificação, $e$ levava pro berçário" (Nilsa, 1968).

"Quando o bebê nascia passava por uma janelinha para o berçário de normal e daío pediatra examinava se tivesse algum problema, porque, se não, tinha horário deles passar a visita. Na verdade quem recebia o recém-nascido eram as funcionárias" (Sônia, 1979).

Pode-se observar que havia uma hierarquia para os primeiros cuidados prestados ao recém-nascido. Na falta de um profissional, o outro assumia, porém a enfermeira estava sempre atenta para que o RN não ficasse sem atendimento. Nesse período, observa-se que não havia a preocupação em aproximar a mãe do bebê, mas em encaminhá-lo para o berçário para realizar exame físico e cuidados de higienização. 0 passo seguinte era encaminhar o recém-nascido, em horário estabelecido, para ser amamentado pela mãe, na unidade de internação, em novo ritual, descrito nas falas a seguir:

"Tinha horário certo das mamadas. As funcionárias trocavam e pesavam os $R N$, e, de 3 em 3 horas, levavam para mamar, com o intervalo da noite. Era um carrinho comprido, cheio de RNs, mas todos com identificação. A identificação era com uma pulseira feita de esparadrapo, o nome escrito com caneta esferográfica e a identificação da plantinha do pé" (Nilsa, 1968).

“... mas assim não tinha uma regra, terminou de dar o banho vou levar o recém-nascido para a mãe. Levava naqueles momentos que era rotina levar. Então às vezes a mãe levava 12 horas para vero 
filho e esse neném ficava afastado sem a mínima necessidade" (Odete, 1987).

Com relação a esses procedimentos, percebe-se que havia uma normatização que deveria ser seguida para que todos os bebês recebessem cuidados e que não houvesse troca; por isso, a identificação era importante. Além disso, infere-se que, na época, havia pouca preocupação com o estreitamento da relação mãe e filho.

No Brasil, os primeiros berçários foram instalados em $1945^{8}$, e somente com a implementação da Portaria GM/MS n. 1016 em 1993, que tornava obrigatória a implantação do Sistema de Alojamento Conjunto, "sistema hospitalar em que o recém-nascido sadio, logo após o nascimento permanece com a mãe, 24 horas por dia, no mesmo ambiente, até a alta hospitalar", esses berçários voltados para o atendimento do recém-nascido sem necessidade de cuidados especiais foram desaparecendo ${ }^{9}$, e os bebês começaram a sair da sala de parto, direto com suas mães, para a unidade de internação. Surgiu, então, a preocupação com a interação mãe-bebê já na sala de parto, promovendo-se o vínculo afetivo e o aleitamento materno precoce $^{10}$.

Buscando adaptar-se às novas determinações do Ministério da Saúde, em 1996, a MCD implantou o Sistema Alojamento Conjunto, que pode ser considerado importante momento de ruptura na assistência à mulher e recém-nascido:

"Em 1996, criou-se o espaço para os berços ao lado do leito da mãe e toda assistência foi modificada. Em termos de funcionários foi aumentado o número, porque, como acabou o berçário, os funcionários de lá foram aproveitados no alojamento. Então se aumentou o número para que a assistência fosse melhor nas 24 horas, que é aquela assistência integral à mãe e ao RN. Foi muito boa essa mudança" (Odete, 1987).

0 Sistema de Alojamento Conjunto propiciou mudanças significativas na assistência de enfermagem e possibilitou uma redistribuição dos profissionais de Enfermagem, o que contribuiu para elevar o número de profissionais no Alojamento Conjunto, permitindo melhor assistência a ambos, mãe e filho.

Em 1989, a Organização Mundial da Saúde (OMS) e o Fundo das Nações Unidas para a Infância (UNICEF) definiram os dez passos para o sucesso da amamentação, com o objetivo de proteger, promover e apoiar o aleitamento materno. ${ }^{11} 0$ quarto passo implicava ajudar as mães a iniciar 0 aleitamento na primeira meia-hora após o nascimento. Anteriormente, era comum no berçário da MCD a utilização de bicos (chupetas), água ou chá como complemento da amamentação, principalmente no período noturno, para os bebês que apresentassem dificuldade na amamentação.
"Era observado o cuidado com a higiene, cada um com seu xuca-xuca pra não ter sapinho. Era tudo precário porque, inclusive em termos de funcionários, eram poucos, e pra contratar não era fácil, tinha que ser autorizado tudo pela Secretaria de Saúde" (Irmã Cacilda, 1956).

"O chá não era prescrito, as funcionárias achavam que era bom. Tinha aquela xuquinha [...] se tinha alguma criança no berçário que não mamasse, aí era prescrita pelo médico a mamadeira, e a mamadeira era feita no lactário, com toda a assepsia, tudo direitinho" (Doraci, 1976).

Baseadas nos seus valores e crenças, as profissionais de enfermagem utilizavam chás ou água para os recém-nascidos como complemento alimentar, principalmente no período noturno. Esta prática era considerada necessária, devido ao longo tempo que os bebês ficavam longe de suas mães, retardando o início da amamentação. Nesse contexto, com poucos profissionais de enfermagem, grande número de RNs e rotinas institucionalizadas, as enfermeiras tinham a preocupação de oferecer cuidado de enfermagem, minimizando o risco de infecção.

Essa realidade está descrita na literatura científica porque, com a rotina de separação prolongada mãe-filho, era comum o uso de água e soro glicosado nos berçários, tanto nos intervalos das mamadas quanto no período noturno ${ }^{12}$.

0 sexto passo para o sucesso da amamentação reforça a importância de não dar ao recém-nascido nenhum outro alimento ou bebida além do leite materno, salvo por indicação médica. Dessa forma, seguindo as determinações da OMS e do UNICEF, e objetivando o recebimento do Prêmio Hospital Amigo da Criança, com o qual foi contemplada em 1996, a MCD mudou sua prática no que diz respeito ao aleitamento materno. Outras práticas também foram sendo modificadas ao longo dos anos:

" $O$ cuidado com o umbigo, naquele tempo se fazia um curativinho. Não se usavam as faixas, era só gaze que se colocava no umbigo e mercúrio" (Irmã Cacilda, 1956).

"No berçário, o banho era dado com uma luvinha, lavava primeiro a cabecinha, depois o corpo, procurava não molhar o umbiguinho, era só com uma luvinha e fazia o curativo também, colocava uma gaze no coto e despejava mercúrio. Depois eles eram trocados na hora das mamadas e nunca tivemos problema de afogamento, de regurgitare assustar. A maioria mamava no seio" (Nilsa, 1968).

"Fizemos mudanças também em relação ao recémnascido. Todos os bebês tomavam banho quando 
nasciam; saíam da sala de parto e iam direto para o berçário, onde havia uns tanques com uns torneirões e todos eles tomavam banho. Era uma loucura e, graças a Deus e devido aos congressos e aos novos ensinamentos, conseguimos abolir essas práticas" (Ana Maria, 1973).

As mudanças nas práticas de cuidado ao recém-nascido, principalmente com o coto umbilical, higiene corporal e controle de infecção do ambiente e dos equipamentos foram sendo implementadas pelas enfermeiras ao longo dos anos. Nas suas falas, as enfermeiras demonstram que os avanços e os conhecimentos técnico-científicos aprendidos, tanto na literatura quanto nos eventos científicos, contribuíram para essas mudanças.

Percebe-se que as enfermeiras da MCD reconheciam, valorizavam e colocavam em ação o conhecimento técnicocientífico que dominavam. Seu saber permitia-Ihes realizar algumas mudanças nas rotinas institucionalizadas, porém sem ultrapassar os limites permitidos pelo poder institucionalizado.

\section{As mães não eram donas dos filhos}

Como os recém-nascidos só eram levados para as unidades de internação no horário da amamentação, de três em três horas, permanecendo na unidade de berçário por longo tempo, sob os cuidados da enfermagem, essas profissionais consideravam que deveriam determinar regras para as mães, quando os bebês se encontrassem com elas, tanto em relação à amamentação quanto à vestimenta. Assim, as mães não se sentiam responsáveis pelos cuidados que deveriam ser prestados aos seus filhos, ou seja, "não se sentiam donas de seus filhos".

"[...] eram unidades com 11 leitos, e o bebê, quando ia mamar, ficava com a mãe na cama. Na hora de recolher os nenéns, recolhia tudo, independente se já tinha conseguido pegar no peito. Então era uma assistência muito prejudicada, digamos, em termos de aleitamento materno era tudo errado, não tinha livre demanda, tinha horário imposto e aquele horário que ele chegava era obrigado a mamar" (Odete, 1987).

"Nesta época não tinha surgido a AIDS. A mãe que tinha pouco leite pedia para outra amamentar seu filho" (Sônia, 1979).

"Na época, as mães que recebiam alta iam para a salinha de estudo do berçário, e lá o residente ou a enfermeira dava orientação sobre cuidados com a criança. Essa orientação começou com a nova estrutura do berçário. Era comum o uso da mamadeira e eu orientava como deveriam ser os cuidados de limpeza e preparo. 0 aleitamento materno passou a ser incentivado pouco a pouco" (Coleta, 1972).

As falas dos sujeitos do estudo revelam que, no início do funcionamento da maternidade, não havia preocupação com a prática da amamentação, o que importava era seguir os horários estabelecidos para saída e retorno do recém-nascido ao berçário. Era comum a utilização do leite de outra mulher, conhecido como aleitamento cruzado, assim como o uso de mamadeira, caso a mãe referisse não ter condições para amamentar. Essas práticas começaram a ser questionadas a partir da implantação do AC.

Até 1970, a corporação médica valorizava o leite industrializado como solução nos casos de hipogalactia, pois o índice de aleitamento materno era muito pequeno, além de o marketing dos leites artificiais ser bastante comum e inclusive utilizar profissionais de saúde para vender seus produtos ao público em geral' ${ }^{13}$.

"[...] eu sei da história que a Nestlé precisou fortalecer a empresa, ela promoveu o desmame para ter consumidores do leite e aí foi tudo pro berçário" (Irmã Cacilda, 1956).

A indústria do leite artificial tinha poder de interferir no modo de cuidar e alimentar os recém-nascidos. Afastando o bebê de sua mãe e dificultando esse contato, o recurso seria o leite artificial. Essa cultura permaneceu por longo período no Brasil.

Nos anos 1980, devido à reivindicação de organizações não governamentais e organizações governamentais, iniciaram-se confrontos com a indústria de leite artificial, surgindo diversas estratégias com objetivo de aumentar a prevalência da amamentação no Brasil. A partir daí, a importância da amamentação exclusiva ficou claramente estabelecida ${ }^{13} \mathrm{e}$ a supressão do aleitamento cruzado foi recomendada para evitar a transmissão de doenças ${ }^{14}$.

Foi possível modificar o cenário do cuidado ao RN, quando a enfermeira Evanguelia liderou movimento com os profissionais da MCD, para conquistar o título Hospital Amigo da Criança em 1996. Porém, as mudanças nas práticas de cuidado para melhorar a relação mãe/recémnascido provocavam inquietação e ansiedade nas enfermeiras:

"Um dos passos mais dificeis foi transformar as unidades de internação obstétrica em sistemas de alojamento conjunto. Ou seja, o berçário tradicional deveria ser extinto, pois não se admitia mais a separação do binômio mãe e filho. Foi uma batalha difícil, mas conseguimos" (Evanguelia, 1976). 
"Depois, graças a Deus, a gente foi mudando, foi trabalhando com as funcionárias, pra mãe ter 0 direito de ver o neném. Isso de abrir na unidade, no inverno, à noite, a gente pedia para as mães não abrirem muito, só espiar o bebê, porque era por causa do frio. Tinham funcionárias que pensavam que eram donas do neném (risos). Eu sempre achei importante essa coisa do toque" (Sônia, 1979).

"A figura do neném já existia dentro da unidade, mas o funcionário que cuidava da mãe não enxergava aquele neném, porque não era dele, era do berçário. Ea partir do momento em que passou a ser responsabilidade da funcionária do $A C$, foi necessário todo um trabalho de treinamento para entender que aquele neném sempre esteve ali e nada ia modificar, só ia ter mais condições de cuidar da mãe e do filho juntos. Mas foi uma resistência da Enfermagem, esse pavor foi bem nítido naquele momento" (Odete, 1987).

$\mathrm{Na}$ modalidade de berçário da época, o poder institucional dificultava a relação mãe-filho, subestimando a necessidade que os pais tinham de cuidar, tocar, observar, enfim, conhecer seu filho. 0 controle e a sujeição objetivando tornar o indivíduo dócil e útil era uma política de coerção estabelecida pelos profissionais de enfermagem, ensinando os pais e as mães a fazer o que os profissionais queriam e a operar como eles queriam ${ }^{15}$. Ao ser instalado o Alojamento Conjunto, os profissionais perderam esse controle, pois esse sistema colocava o recém-nascido ao lado da sua mãe, favorecendo o relacionamento materno-infantil e obrigando os profissionais de saúde a reverem suas práticas, porquanto 0 ato de cuidar passava a incluir a coparticipação dos familiares do recém-nascido.

As entrevistadas referem ainda que essa nova modalidade de cuidado mostrou-se como um desafio para as profissionais de enfermagem, gerando a necessidade de adaptar-se às novas exigências. 0 ser humano apresenta dificuldade em aceitar o novo e enfrentar o que lhe parece desconhecido, mesmo que ele já vivencie tal situação sob outra perspectiva. Em nosso entendimento, isso ocorre pelo temor do insucesso, por falta de vivência, ou, muitas vezes, por falta de conhecimento.

\section{0 prematuro era bem embrulhadinho e levado da sala de parto para o berçário de alto risco}

A Sala de Parto da MCD está localizada no térreo e o Berçário de Alto Risco (BAR), no primeiro andar. Havia normas para a transferência dos recém-nascidos prematuros. No entanto, como nos partos prematuros os bebês podiam nascer deprimidos, as enfermeiras tinham muita preocupação com a maneira como eram levados para 0 Berçário de Alto Risco:
"O prematuro era bem embrulhadinho e levado da Sala de Parto para o Berçário de Alto Risco. Era uma norma" (Doraci, 1976).

"Nos partos prematuros, os recém-nascidos nasciam deprimidos, na época o neonatologista não ia atender na sala de parto, não tinha residência médica em neonatologia; então, a gente tinha que sair com aquele recém-nascido prematuro, correndo da sala de parto, subir as escadarias para levá-lo para o berçário de alto risco para o neonatologista atender. Conversei com o chefe da neonatologia que era inadmissível que a gente tinha que transferir essas parturientes bem próximo ao período expulsivo para dar condições de elas parirem no centro cirúrgico, e para o recém-nascido já ser atendido ali e transferido para o berçário de alto risco ao lado do centro cirúrgico. Eu tinha uma preocupação muito séria de que de repente a técnica de enfermagem ou a atendente, ou a parteira, enfim, pudessem cair na escada com o recém-nascido" (Odaléa, 1985).

As enfermeiras da MCD demonstraram preocupação tanto com o aquecimento do recém-nascido prematuro quanto com a sua integridade física quando eram transferidos da sala de parto para o Berçário de Alto Risco. Com o seu saber-poder buscaram, em consonância com o poder-saber do médico, mudanças na prática estabelecida, ou seja, reformular 0 ambiente previsto para o nascimento do neonato prematuro. Ao mesmo tempo em que se constituem como instrumento para a organização, as normas também são indispensáveis para o bom atendimento ao recém-nascido. Por essa razão, devem ser refletidas, discutidas e reformuladas, sempre que necessário, como se pode ver também em outras falas:

"Os estudantes do hospital infantil, que era anexo, vinham atender as nossas crianças, os nossos prematuros. Começaram a aparecer diarreia e piodermite nas minhas crianças e eu fiquei muito preocupada. Então estava exigindo que eles não trouxessem mais estetoscópio do Hospital Infantil, que lavassem muito bem as mãos, coloquei pro-pé, touca e avental. [...]. Até numa aula o pediatra me convidou pra participar, pra falar sobre os cuidados do prematuro e dos recém-nascidos. Ele falou em tom de brincadeira, a enfermeira Nilsa andou benzendo o berçário, acabou com as diarréias e com as piodermites" (Nilsa, 1968).

"Pessoas estranhas ao serviço não entravam no berçário de alto risco, como medida de prevenção de infecções. Quando necessário, as pessoas eram recebidas na sala ao lado" (Coleta, 1972). 
"Nosso grande problema era fazer desinfecção. Fazia-se com um produto líquido. Era colocado num recipiente e acoplado a um aspirador de pó, mas no sentido oposto para que pudesse ser vaporizado nas paredes e em todo o ambiente. Esse líquido tinha um cheiro fortíssimo. Usávamos máscara, mas, mesmo assim, o cheiro era terrível. Depois fechávamos a porta, de oito a doze horas, e passávamos fita adesiva nas portas para vedar. No Berçário de Alto Risco, fazia-se isso somente na sala de isolamento, que era separada das outras salas. No restante das salas, era feita limpeza uma por uma e de tudo o que continha nela" (Sônia, 1979).

A causa mais comum da incidência dos processos infecciosos nos recém-nascidos era o despreparo do pessoal de saúde. 0 papel da equipe de enfermagem era considerado primordial na proteção do recém-nascido, realizando-se medidas de higiene, desinfecção do ambiente e cuidados com o material utilizado.

As práticas de antissepsia e prevenção de infecções eram preocupação constante das enfermeiras da MCD. Por essa razão, introduziram, no berçário, medidas profiláticas que eram preconizadas, como a lavagem das mãos, a utilização de pro-pé, touca e avental e estetoscópios de uso individual, conseguindo diminuir a incidência de infecções, como diarreias e piodermites. A circulação de pessoas dentro do berçário também foi limitada na instituição, objetivando reduzir as infecções. Um dos problemas vivenciados, como relatado, era com a desinfecção. 0 material utilizado em cuidados de enfermagem não era descartável e não havia equipamentos apropriados para realizar a desinfecção do ambiente. Com seu conhecimento técnico-científico, intuição e tato, as enfermeiras utilizavam-se de artifícios que contribuíam para a proteção dos recém-nascidos.

A literatura científica faz referência à entrada de pessoas no Berçário de Alto Risco, que durante muito tempo foi limitada. 0 uso de pro-pé, touca, avental e máscara era uma recomendação necessária, e os aventais deveriam ser de manga curta e cobrir toda a roupa usada pelo profissional, até a altura dos joelhos. As máscaras deveriam cobrir 0 nariz e a boca e, depois de colocadas, não podiam ser manipuladas. Sua troca deveria ser frequente, e o tempo não deveria exceder uma hora. A touca deveria cobrir todos os cabelos dos profissionais. 0 pro-pé era recomendado para diminuir a entrada de poeira e outras sujidades na unidade de internação. A escovação de mãos, unhas e antebraços também era exigência para o pessoal que trabalhava nas unidades de risco, além da lavagem das mãos entre 0 manuseio de uma criança e outra ${ }^{16}$.

Havia também preocupação com o barulho na unidade de berçário.
"Dentro do BAR tinha muito barulho, até música alta se colocava. Um dia cheguei para uma funcionária de zeladoria que estava limpando o vidro do berçário e disse pra ela que ali dentro tinha crianças que estavam quietinhas dormindo e também tinha mães ali por perto, se podia falar mais baixo, ai ela respondeu: olha, a senhora que chegou ontem quer me mandar? Eu já estou aqui há vinte anos, e sempre falo dessa maneira, ninguém me mandou calar a boca, daí eu saí, e também não disse nada" (Doraci, 1976).

A fala da enfermeira Doraci denota que os funcionários relutavam em aceitar que um profissional recém-admitido viesse desestabilizar o seu modo de trabalhar. Os depoimentos revelam que a adequação do ambiente e a individualização do cuidado tinham o objetivo de promover maior estabilização e organização do recém-nascido, cuidados esses que também reduziam o estresse e favoreciam a conservação de energia necessária ao seu desenvolvimento.

A influência do ambiente das unidades de internação neonatal no desenvolvimento do recém-nascido vem sendo evidenciada ao longo dos anos. Nessa unidade, o recém-nascido fica exposto a níveis de ruído elevados que podem levar a perda auditiva por dano coclear $^{17}$.

A satisfação e o bem-estar do recém-nascido, assim como do trabalhador da saúde, principalmente em locais de estresse e ansiedade, como o berçário de alto risco, são imprescindíveis para a qualidade e a sensibilidade nas práticas de cuidado. Compreendendo o desgaste físico e mental das profissionais de enfermagem neste ambiente, as enfermeiras da MCD demonstravam também que buscavam estratégias defensivas que tinham como objetivo modificar, transformar ou minimizar tal situação.

"Sempre que estava calmo no BAR, íamos arrumar o material, fazer torundas (bolinhas de gaze), bolinhas de algodão, coisas assim. Enquanto as funcionárias trabalhavam, eu tinha sempre um livro para ler para elas, assim sobre pensamentos positivos, ou livros de autoajuda. [...] fazíamos também algumas brincadeiras não só conosco, mas com alguns pediatras. Isto ocorria principalmente quando não tinha nenhum neném no respirador, e o número dos pacientes era pequeno" (Sônia, 1979).

As profissionais de saúde das unidades de internação neonatal confrontam-se diariamente com situações estressantes. Por isso, a utilização de mecanismos de defesa como os utilizados pelas enfermeiras da MCD é importante. Embora a MCD não contasse com uma filosofia de humanização específica, observa-se que 
as enfermeiras tentavam valorizar e motivar os profissionais de saúde, buscando estabelecer relações interpessoais saudáveis e prazerosas.

Um dos estressores enfrentados pelos profissionais de saúde nas unidades de risco, na grande maioria das vezes, é a falta de coleguismo e de compromisso da equipe, daí a importância do papel dos líderes da equipe, avaliando as atitudes dos profissionais e propondo alternativas saudáveis. 0 diálogo construtivo, valorizando a amizade e o respeito mútuo, e o estabelecimento de mecanismos de adaptação que tornem o ambiente mais acolhedor e agradável são fundamentais para que a equipe possa atender com maior qualidade as mulheres, famílias e recém-nascidos ${ }^{18}$. As atitudes dos profissionais de saúde demonstrando apoio e solidariedade contribuem para o bem-estar psicossocial e facilita a adaptação da família à nova realidade ${ }^{19}$.

Entende-se que, em se tratando de unidades de risco, a capacidade técnica é fundamental, mas a compreensão e a interação entre os profissionais de saúde e os sujeitos de cuidado em termos dos aspectos relacionados às necessidades psicoafetivas também devem ser respeitadas e valorizadas ${ }^{20}$.

\section{CONCLUSÃO}

No tocante às práticas de cuidados prestadas aos recém-nascidos, a história mostra que a MCD passou por muitas transformações importantes e desafiantes para as enfermeiras. Se em dado momento o recém-nascido permaneceu isolado, em outro passou a ser cuidado com a sua mãe, na unidade de Alojamento Conjunto. Essa mudança mostrou-se como uma situação causadora de conflitos, resistências e tensões, pois, nessa nova modalidade de cuidar, tanto a mãe quanto o profissional de saúde buscavam exercer o seu poder.

Assim, foi necessário estabelecer relações que possibilitaram a mobilidade do poder, do saber e do fazer da mãe e dos profissionais de enfermagem. Essas relações propiciaram melhor interação mãe/recém-nascido/ profissional de enfermagem e desencadearam mudanças significativas nas práticas de cuidado, principalmente as relativas à prevenção de infecções por meio do cuidado com o ambiente e os equipamentos, cuidados com o curativo umbilical, banho do recém-nascido, aleitamento materno e estabelecimento de vínculo precoce mãe e filho, entre outras.

Acredita-se que o presente estudo possibilitou conhecer o cotidiano do trabalho das enfermeiras, iluminando o interior das práticas de cuidado ao recémnascido e as relações de poder-saber, fortalecendo sua identidade e colaborando para a construção profissional, mostrando assim que a Enfermagem faz parte de um processo que está interligado ao contexto sócio-histórico, político e cultural.

\section{REFERÊNCIAS}

1 Pereira NV. Associação Irmão Joaquim, 100 anos de amor ao próximo: histórico da Associação Irmão Joaquim por ocasião do seu centenário1902-2002. Nereu do Vale Perreira. Florianópolis: Associação Irmão Joaquim; 2002.

2 Inauguração da Maternidade Carmela Dutra. A Gazeta, 1955 Jul 3; 3-12.

3 Maternidade Carmela Dutra. Diário da Tarde, 1955 Jun 4; 29.

4 Fink A. How to sample in surveys. The Survey Kit (6). Thousand Oaks: Sage; 1995.

5 Minayo MCS. 0 desafio do conhecimento: pesquisa qualitativa em saúde. São Paulo : Hucitec-Abrasco; 2004.

6 Foucault M. Arqueologia do saber. $6^{\text {a }}$ ed. Rio de Janeiro:Forense Universitária; 2007.

7 Foucault M. Microfísica do poder. Rio de Janeiro: Graal; 2006.

8 Valman HB. 0 primeiro ano de vida. São Paulo: Manole; 1987.

9 Ministério da Saúde(BR). Portaria n.1.016, de 26 de agosto de 1993. Normas básicas de alojamento conjunto. Brasília (DF); 1993.

10 Organização Mundial da Saúde- OMS. Fundo das Nações Unidas para a Infância. Visa promover, proteger e apoiar a prática do aleitamento materno. Geneva: WHO; 1989.

11 Organização Mundial de Saúde- OMS. Fundo das Nações Unidas para a Infância. Dez passos para sucesso do aleitamento materno. Brasília (DF): Ministério da Saúde; 1993.

12 Toma TS, Monteiro CA. Avaliação da promoção do aleitamento materno nas maternidades públicas e privadas do município de São Paulo. Rev Saude Publica. 2001; 35(5): 409-14.

13 Juruena GS, Malfatti CRM. A história do aleitamento materno: dos povos primitivos até a atualidade. Rev Digital Buenos Aires. [internet]. 2009 [citado 2010 jun 29]; 13(129). Disponível em http://www.efdeportes.com .

14 Del Ciampo LA, Ricco RG. Aids e aleitamento natural. J Pediatr. $1989 ; 65(1 / 2): 46-8$.

15 Foucault M. Vigiar e punir: nascimento da prisão. Petrópolis (RJ): Vozes; 2006.

16 Pizzato MG, Da Poian VR. Enfermagem neonatológica. $2^{\mathrm{a}}$ ed. Por to Alegre: Luzzatto Ed; 1985.

17 Ministério da Saúde (BR). Atenção humanizada ao recém-nascido de baixo peso: Método Mãe-Canguru: manual do curso. Brasília (DF): Ministério da Saúde; 2002. 
18 Leite MA, Vila VSC. Dificuldades vivenciadas pela equipe multiprofissional na unidade de terapia intensiva. Rev Latino-Am Enfermagem. 2005; 13(2): 145-50.

19 Fraga TF, Amante LN, Anders JC, Padilha MICS, Henckemaeir L, Costa R, et al. Percepção das mães sobre o processo comunicacional na unidade de terapia intensiva neonatal. Rev Eletr Enferm. [internet]. 2009 [citado 2010 jun 30]; 11(3): 612-19. Disponível em http://www.fen.ufg.br.

20 Progianti JM, Barreira IA. Parteiras, médicos e enfermeiras: a aquisição de habilidades profissionais na assistência à parturiente (Rio de Janeiro 1934/1949). Esc Anna Nery. 2001; 5(3): 307-14.

\section{NOTA}

${ }^{a}$ No decorrer do estudo, Ottille Hammes será nominada como Irmã Cacilda, pois este era o nome que utilizava à época, devido ao fato de ser religiosa na Congregaçã o das Irmãs da Divina Providência. 